\title{
Reproductive risk factors for culling and productive life in large dairy herds in the eastern United States between 2001 and 2006
}

\author{
A. De Vries, ${ }^{* 1}$ J. D. Olson, $\dagger$ and P. J. Pinedo* \\ *Department of Animal Sciences, University of Florida, Gainesville 32611 \\ †Pfizer Animal Health, Ft. Collins, CO 80528
}

\begin{abstract}
Knowledge of reproductive risk factors for culling is useful in making insemination and culling decisions and helps motivate efforts to reduce or eliminate risk factors. The objective of this study was to describe survival and reproductive risk factors for culling in Holstein dairy herds with at least 200 cows. Results were calculated from 2,345,015 DHI lactation records from 727 herds with at least 200 cows from 2001 to 2006. Herds were located in 36 states primarily located east of the Mississippi River. Kaplan-Meier survival curves were obtained and daily hazards of culling were calculated with the actuarial method. Cox regression was performed with the GLIMMIX procedure in SAS (SAS Institute Inc., Cary, NC). The hazard of culling increased with parity number. Cows in their sixth parity had 3 times greater hazards than cows in their first parity. Medium remaining productive life for cows calving in parity 1 to 6 were 907, 697, 553,469, 423, and 399 d, respectively. Daily hazards of culling first peaked approximately $30 \mathrm{~d}$ after calving and then again later in lactation, after $280 \mathrm{~d}$, for older cows. Hazards for first-parity cows peaked earlier, around d 10 after calving, and the first-parity cows had lower risks of culling later in lactation than older cows. Pregnant cows had 3 to 7 times lower hazards of culling than open cows. Hazards of culling increased for cows that had greater calving difficulty, gave birth to males or twins, were in herds with shorter days to first insemination, or had longer days to conception. The possible to likely use of a synchronized breeding program increased from $21.9 \%$ in 2001 to $41.4 \%$ in 2006. Cows in herds that did not use a synchronized breeding program had slightly lower risks of culling than those in herds that at least possibly used a synchronized breeding program.
\end{abstract}

Key words: reproduction, culling, survival analysis

Received July 15, 2009.

Accepted October 6, 2009.

${ }^{1}$ Corresponding author: devries@ufl.edu

\section{INTRODUCTION}

Cow replacement is a major cost of dairy production (Fetrow et al., 2006). Replacement costs are typically several hundreds of dollars per cow per year (MSWFT, 2009). Quantification of the association between risk factors and culling is useful for making insemination and culling decisions and helps motivate efforts to reduce or eliminate the risk factors. Parity and stage of lactation affect the economic losses of a culled cow (De Vries, 2006). Many studies have documented risk factors for culling (e.g., Beaudeau et al., 2000; Weigel et al., 2003; Hadley et al., 2006). Greater parities have increased risk of culling (Hadley et al., 2006; Hare et al., 2006). Within parity, the daily risk of culling is typically greater early in lactation, then increases again later in lactation (Godden et al., 2003; Dechow and Goodling, 2008). Hazard functions for different parities and survival curves for remaining productive life, defined as the time from calving to culling, per parity are scarce but would provide further insight into when cows leave the herd.

Failure to conceive or remain pregnant is a major reason why cows are culled (Bascom and Young, 1998; Hadley et al., 2006), but few recent studies have examined the association of reproductive factors with culling. Sewalem et al. (2008) quantified the effects of calving ease, calf size, number of inseminations, days from calving to first insemination, days from first insemination to conception, and days to conception on functional productive life in Canadian cows. Rajala-Schultz and Gröhn (1999) studied the effects of disease and reproductive performance on culling in Finnish cows. Schneider et al. (2007) reported on the effects of mastitis and pregnancy status on culling in Swedish dairy cows. Beaudeau et al. (2000) summarized the literature on the effects of metritis, cystic ovaries, dystocia, retained placenta, abortion, and stillbirth on culling.

Another reproductive risk factor for culling may be reproductive breeding program such as natural service bulls, AI following estrus detection, or AI following estrus synchronization. Miller et al. (2007) proposed a method to determine from insemination dates the like- 
lihood of the use of a synchronized breeding program (SBP), such as Ovsynch, on dairy farms. It is not clear how the use of an SBP is associated with culling and survival.

Studies by Sewalem et al. (2008), Weigel et al. (2003), and Schneider et al. (2007), among many others, were performed using the Survival Kit (Ducrocq and Sölkner, 1994). This program for survival analysis allows for the inclusion of random effects, which is not ordinarily available in procedures for survival analysis in SAS (SAS Institute Inc., Cary, NC). An alternative approach to survival analysis is the use of ordinary logistic regression (Allison, 1995). This approach may be extended to include random effects using generalized linear mixed models, but examples using SAS software have not been found in the literature.

The objective of this study was to describe survival and risk factors for culling and survival separately by parity for different calving difficulty scores, calf sex, days to first insemination, likelihood of SBP, and pregnancy status (open vs. pregnant). The analysis was limited to Holstein cows in herds located primarily in the eastern United States with at least 200 Holstein cows.

\section{MATERIALS AND METHODS}

\section{Data Source}

Available data were 14 million DHI lactation records from 36 states primarily located east of the Mississippi River. The records were obtained from Dairy Records Management Systems in Raleigh, North Carolina. Each lactation record started with a calving date between January 1, 2001, and December 31, 2006. Lactation records primarily included data on milk production (up to 20 test-days), reproduction, calving difficulty scores, and culling. Data about diseases, facilities, or management practices were not available.

\section{Data Edits}

Only Holstein lactation records were used. For each lactation record, the dates (if any) of calving, first insemination, conception, culling, and last known event in the herd were determined. Available events were calving, DHI milk test, insemination, dry-off, or removal from the herd. The last known event date was the last known calving date, insemination date, milk test date, cull date, or dry-off date, whichever was latest. The most recently documented event date was November 23, 2008. Records that ended with a subsequent calving date were considered completed. Records that did not end in a subsequent calving date or a cull date were considered censored at the last known event date. How- ever, events after 1,095 d since calving were ignored for censored cows and the last known event date was set to $1,095 \mathrm{~d}$ after the calving date.

The cull date was the last known reported status date with the reported status code for culled. Cows that left the herd with reported reason dairy were censored at the last known status date. Such cows were probably sold to another dairy farm and continued production. All other reported culling reasons were included, including death.

First insemination dates could be determined only for records that were not completed because records for completed lactations of the same cow contained only the date of the insemination that resulted in the pregnancy that led to calving. Days to first insemination greater than 200 were not considered.

Conception dates for completed records were calculated by adding the reported days to conception to the calving date that started the record. However, if the resulting gestation length was less than $220 \mathrm{~d}$ or more than $300 \mathrm{~d}$, then conception dates were calculated as the next calving date minus $280 \mathrm{~d}$. Conception dates that resulted in abortion could not be determined. Thus, only the conception date that resulted in a subsequent calving was used in completed lactations.

If the record was not completed but a due date was reported and the interval between the due date and last reported insemination date was less than 278 or more than $282 \mathrm{~d}$, then the conception date was calculated as $280 \mathrm{~d}$ before the due date. If a cow did not have a reported due date but was reported pregnant, then her last insemination date was used as the conception date.

Cows were considered pregnant if their last reported pregnancy status was $\mathrm{P}$ or $\mathrm{E}$, indicating that the pregnancy was reported by the dairy producer. In all other cases for lactations that were not completed, the cow was considered open regardless of insemination history. The last reported pregnancy status for cows that completed the lactation was pregnant.

Pregnancy status at $90 \mathrm{~d}$ after calving was also determined. If the last known insemination date was before $90 \mathrm{~d}$ after calving and the cow was in the herd at least $90 \mathrm{~d}$ after calving, then the pregnancy status at $90 \mathrm{~d}$ after calving was set to the last reported pregnancy status. In all other cases where the cow was still in the herd at least $90 \mathrm{~d}$ after calving, the pregnancy status on d 90 was set to open. The same procedure was used to determine pregnancy status at 150,210, and $270 \mathrm{~d}$ after calving.

Milk yield at 90 and $270 \mathrm{~d}$ after calving was calculated as a linear interpolation from both test-days and test-day milk yields the nearest before and after d 90 or 270 if the cow was not tested on that particular day. 
For each record, the number of cow-days in the parity was calculated as the number of days between the calving date and the last known event date. Cow-days for open cows were calculated as either the number of days between calving and conception that resulted in a reported pregnancy or the last known event date, whichever was earlier. Cow-days for pregnant cows were calculated as either the number of days between conception and calving or the last known event date, whichever was earlier. Remaining productive life was defined as either the number of days from calving in the parity of interest to the time the cow left the herd or her last known lifetime event date.

\section{Herd Measures}

Several herd measures were calculated per herd per year from the edited lactation records. Average size, annual cull rate, and percentage of cows per parity were calculated from the counted cow-days in a calendar year and the number of cows culled in a calendar year. Annualized culling risks for open, pregnant, and all cows were calculated as number of cows that left the herd $\div$ number of cow-days at risk $\times 365$. The data set was limited to herds with herd sizes of at least 200 cows in each of the years from 2001 to 2006 .

The year of calving determined the year for which mature equivalent milk, voluntary waiting period (VWP), days to first insemination, and days to conception were calculated. Herd-days to first insemination were calculated as the average days to first insemination per herd per year. Five categories were created based on 20th, 40th, 60th, and 80th percentiles of the distribution of all herd-years of average days to first insemination. Herd VWP per year was calculated as the number of days after calving by which $10 \%$ of the cows with a first insemination had received their first insemination (Miller et al., 2007).

For each herd and year, the likelihood of the use of an SBP was determined based the method of Miller et al. (2007) but with some adjustments. The assumption was that herds using an SBP had an unequal distribution of first inseminations across days of the week because synchronized cows are typically inseminated on a certain day of the week. First inseminations based on estrus detection would be more equally distributed among days of the week.

Miller et al. (2007) based their classification of SBP on the chi-square of the distribution of first inseminations across the week $\left(\bar{\chi}_{h}^{2}\right)$ and the maximum percentage of first inseminations on a single day of the week (\% max). In the current study, the day of conception was used if the cow conceived before $101 \mathrm{~d}$ after calving for completed lactations. For lactations that were not completed, the day of first insemination was used. Herd-years with fewer than 30 inseminations were excluded. The method used by Miller et al. (2007) resulted in an unequal distribution of first inseminations across the week in herds that were thought to be unsynchronized. Therefore, the sum of inseminations $(\boldsymbol{\Sigma N})$ was also used to separate the herd-years that were supposed to be unsynchronized into not synchronized and unlikely synchronized. Herd-years with $P\left(\chi^{2}\right)>0.2$ were considered to be not synchronized. For the other cases, the actual $\bar{\chi}_{h}^{2}$ value was used. Herd-years that did not satisfy $\% \max >35,\left(\bar{\chi}_{h}^{2}>45\right.$ and $\left.\Sigma \mathrm{n}<50\right)$, or $\left(\bar{\chi}_{h}^{2}>40\right.$ and $\left.\Sigma \mathrm{n}<40\right)$ were considered unlikely synchronized. Otherwise, if $\bar{\chi}_{h}^{2}<84$, the herd-year was possibly synchronized. If $84 \leq \bar{\chi}_{h}^{2} \leq 400$, the herd-year was probably synchronized. The remaining herd-years with $\bar{\chi}_{h}^{2}>400$ were classified as likely synchronized. These edits resulted in the same categories for possibly, probably, and likely synchronized herds as in Miller et al. (2007).

\section{Statistical Analyses}

Version 9.2 of SAS was used for all data editing and statistical analyses. Hazard functions for pregnant and open cows were obtained with the actuarial method in the LIFETEST procedure.

Survival curves of remaining productive life by parity were obtained with the PHREG procedure with the fixed effect of calving year. Strata of the effect of interest were used in the analysis of calving difficulty score, calf sex, SBP, herd-days to first insemination, and pregnancy status at 90,150, 210, and $270 \mathrm{~d}$ after calving. The PHREG procedure with the fixed effect of calving year was also used to calculate survival by days since calving for open cows and by days since conception for pregnant cows. The fixed effect of herd was not included; therefore, survival curves represented all cows rather than herd averages.

Hazard ratios of cows culled in the current parity were calculated with the GLIMMIX procedure and the complementary log-log link function with the binomial distribution based on the method described by Allison (1995) for tied or discrete data with the GENMOD procedure. The CONGRA optimization technique was specified because the data set was large. Survival time was categorized in steps of $30 \mathrm{~d}$ and fit as a fixed effect. This formulation resulted in a Cox regression model. Year was included as a time-dependent effect and herd as a random effect. Only the fixed effect of interest 
Table 1. Descriptive statistics of 727 large DHI dairy herds in the eastern United States from 2001 to 2006

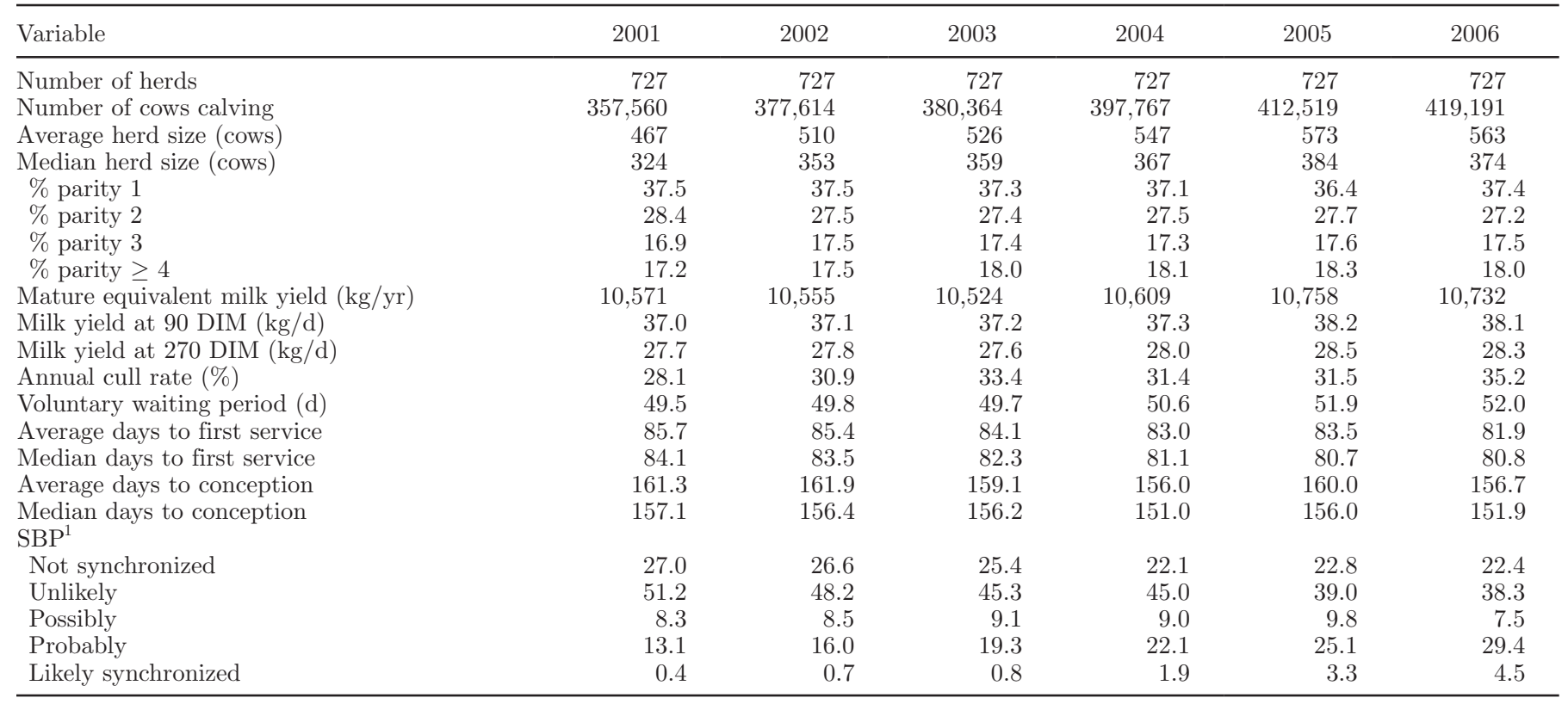

${ }^{1}$ Likelihood of synchronized breeding program.

(e.g., calving difficulty score) was also included in the model. Cox regression was performed separately for each risk factor. Lactation lengths greater than $730 \mathrm{~d}$ were censored at $730 \mathrm{~d}$ to avoid convergence problems.

Proportionality of hazards for the different levels of the risk factor of interest within parity was evaluated by plots of the $\log$ of the negative log of the estimated survivor function against log time. The LIFETEST procedure was used with the risk factor of interest specified as strata. Hazards were proportional if the curves on these plots were approximately parallel across strata (SAS Institute Inc., 2008).

Hazard ratios and the $95 \%$ confidence intervals were calculated by exponentiation of the parameter estimates (Allison, 1995; Collett, 2003). Analyses were done separately by parity unless noted specifically where parity was included as a fixed effect in the model.

\section{RESULTS}

\section{Descriptive Statistics}

After edits, a total of 2,345,015 lactation records were available from 727 herds. Average herd size increased from 467 in 2001 to 573 in 2005 (Table 1). Median herd size ranged from 324 to 384 cows. Average mature equivalent milk yield varied from 10,524 to $10,758 \mathrm{~kg}$. Average milk yield at 90 and 270 DIM ranged from 37.0 to 38.2 and from 27.6 to $28.5 \mathrm{~kg} / \mathrm{d}$, respectively.

Annual cull rates were approximately $32 \%$, with approximately $37 \%$ of the cows in their first parity and
$83 \%$ within the first 3 parities. Average VWP increased slightly from 49.5 to $52.0 \mathrm{~d}$ in 2006; median VWP was similar. Average days to first service decreased from 85.7 in 2001 to 81.9 d in 2006. Average days to conception varied between 156.0 and 161.9.

In 2001, $27.0 \%$ of the herds did not use an SBP, but this decreased to $22.4 \%$ in 2006 . In $2001,21.8 \%$ of the herds possibly to likely used an SBP. The possible to likely use of an SBP increased to $41.4 \%$ in 2006 . Thursday was the day of the week with the most inseminations in all SBP categories except not synchronized. Friday was the day of the week with the second most inseminations. In herds that likely used an SBP, $54 \%$ of all inseminations were on Thursday and $36 \%$ were on Friday. The herd-years classified as not synchronized had a reasonably equal distribution of inseminations across the days of the week, with the maximum of $19 \%$ on Monday.

Censoring of lactation records increased with year of calving to $23.7 \%$ for cows that calved in 2006 . Of the cows that calved for the first time in 2006, $46.8 \%$ had left their herd by the end of the study. Because censored records were present, average remaining productive life was not calculated.

\section{Risk Factors}

Parity. The risk of culling increased with parity. Hazard ratios of cows leaving the herd were 1, 1.51, $2.14,2.68,3.11$, and 3.46 for parities 1 to 6 , respectively. Annualized (365-d) culling risks for all cows in parities 


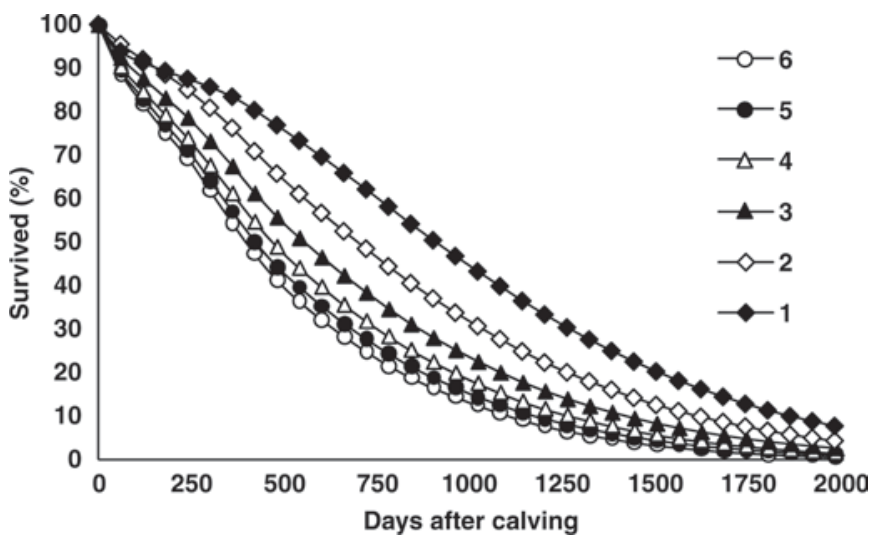

Figure 1. Remaining days of productive life by parity of calving of interest in 727 large DHI dairy herds in the eastern United States from 2001 to 2006. Symbols denote number of parity.

1 to 6 were $29.2,37.6,46.4,53.6,59.3$, and $63.3 \%$, respectively. For parities 1 to 6,90 th percentile survival times were $158,155,89,65,57$, and 53 d since calving, respectively (Figure 1). Similarly, median survival times were 907, 697, 553, 469, 423, and 399 d, respectively, and 10th percentile survival times were $1,856,1,611$, $1,415,1,276,1,176$, and $1,108 \mathrm{~d}$, respectively.

Reproductive Status. Cows diagnosed open had 2.7 to 6.7 times greater hazard of culling than cows diagnosed pregnant (Table 2). The hazard ratio increased with days since calving. Longer days open reduced survival more in older cows than in first-parity cows. At the day of pregnancy diagnosis, $100 \%$ of the cows were present. Pregnancy increased survival. Cows that were diagnosed pregnant on the day of pregnancy diagnosis might have calved again 150 or 365 d later, thereby reducing their risk of survival.

Pregnant cows were at a greater hazard of culling when they had longer days to conception (Table 3 ). First-parity pregnant cows that conceived after $390 \mathrm{~d}$ were twice as likely to be culled as cows that conceived by $150 \mathrm{~d}$ after calving. This effect was smaller for older cows. The hazard increased between 280 and 340 d after the conception date. Gestation lengths much greater than $280 \mathrm{~d}$ are unlikely; therefore, either these cows were culled at calving or the calving event was not reported and the cow entered the next parity. Fresh cows were typically more at risk for leaving the herd than pregnant cows.

The hazard for first-parity open cows first peaked within $10 \mathrm{~d}$ after calving (Figure 2). The hazard for older cows first peaked at approximately $30 \mathrm{~d}$ after calving. The lowest hazards were observed around $70 \mathrm{~d}$ after calving, after which the hazard gradually started to increase again. The hazard started to increase greatly after d 300 for first-parity cows, but earlier for older cows. Median days to culling for parities 1 to 6 were $538,415,371,346,332$, and 325 d, respectively. Hazard ratios and annualized risk of culling for open cows were greater for greater parity cows (Table 4).

The daily hazard of pregnant cows leaving the herd was very low until approximately $40 \mathrm{~d}$ after conception because cows that conceived had not been diagnosed and reported pregnant (Figure 3). Older cows had greater hazards than first-parity cows. Hazards for pregnant

Table 2. Hazard ratios (HR) of culling within the parity and percentage survival in the herd for days after pregnancy diagnosis by parity and pregnancy status at 90,150,210, and $270 \mathrm{~d}$ after calving in 727 large DHI dairy herds in the eastern United States from 2001 to $2006^{1}$

\begin{tabular}{|c|c|c|c|c|c|c|}
\hline $\mathrm{DIM}^{2}$ & HR, open & $95 \%$ CI HR, open & \multicolumn{4}{|c|}{ Survival (\%) } \\
\hline \multicolumn{7}{|l|}{ Parity 1} \\
\hline Day 90 & 2.66 & $2.60-2.72$ & 94.6 & 83.0 & 98.5 & 89.8 \\
\hline Day 150 & 2.83 & $2.78-2.88$ & 92.3 & 77.9 & 97.3 & 87.5 \\
\hline \multicolumn{7}{|l|}{ Parity 2} \\
\hline Day 90 & 2.97 & $2.91-3.03$ & 91.6 & 69.9 & 97.1 & 83.6 \\
\hline Day 150 & 3.63 & $3.57-3.68$ & 85.2 & 61.5 & 95.3 & 80.9 \\
\hline Day 210 & 4.89 & $4.81-4.97$ & 78.1 & 52.1 & 94.4 & 78.3 \\
\hline Day 270 & 6.65 & $6.54-6.76$ & 68.7 & 42.0 & 92.1 & 75.0 \\
\hline \multicolumn{7}{|l|}{ Parity 3} \\
\hline Day 90 & 2.86 & $2.80-2.93$ & 89.0 & 62.4 & 95.8 & 78.6 \\
\hline
\end{tabular}

${ }^{1} \mathrm{HR}$, open = hazard ratio of open cows vs. pregnant cows (hazard $=1$ ) in the parity; $95 \%$ CI HR, open $=95 \%$ CI for hazard ratio.

${ }^{2}$ Pregnancy diagnosis at 90, 150, 210, and $270 \mathrm{~d}$ after calving. 

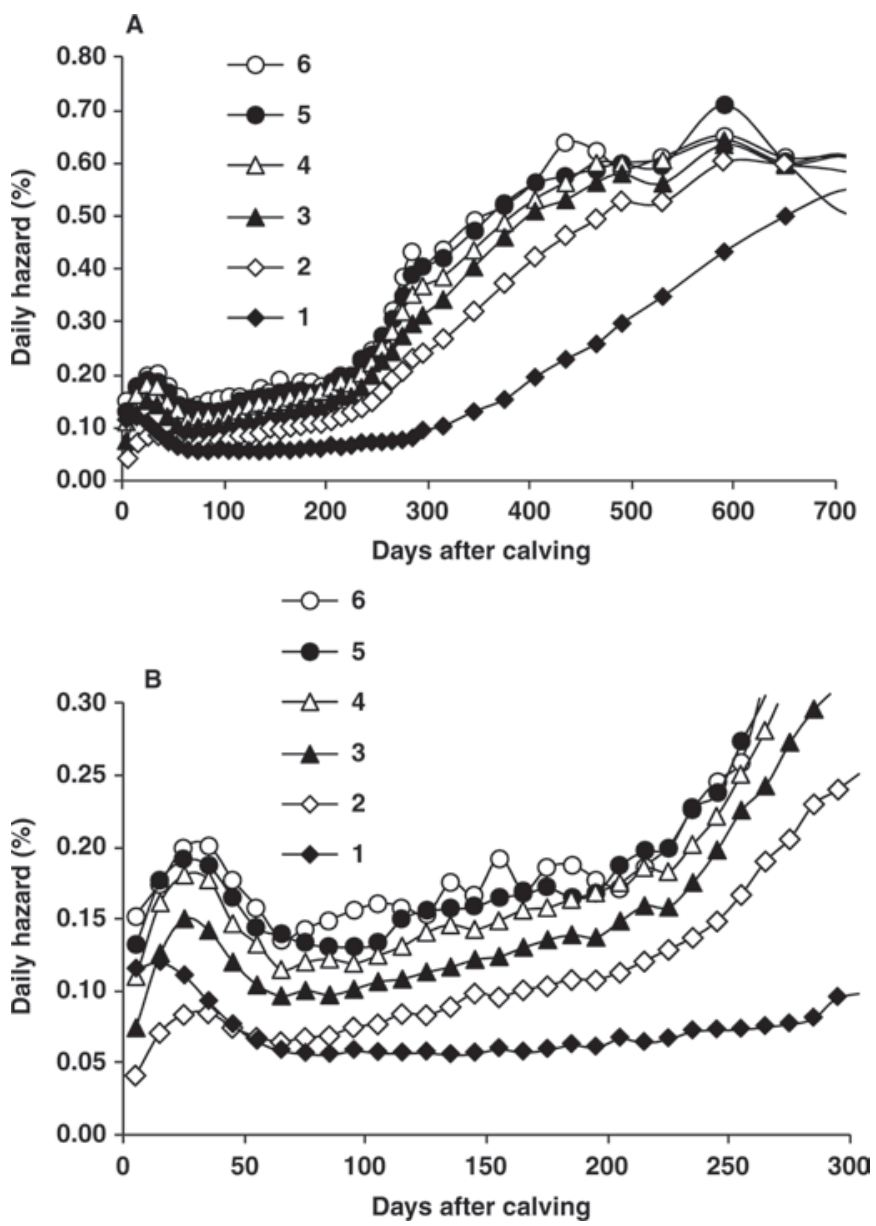

Figure 2. Daily hazard of culling in the parity for open cows by parity in 727 large DHI dairy herds in the eastern United States from 2001 to 2006. Figure B is a subset of figure A. Symbols denote number of parity. cows were approximately one-quarter of the hazards for open cows. The hazards increased greatly at the time of calving. Of the pregnant cows that were culled, $11.2 \%$ were reported to have left for low production reasons and $11.8 \%$ for reproduction reasons. These cows were probably found open and were culled.

Calving Difficulty Score. Difficult calvings increased the hazard of culling for every category (Table 5 ). Cows with a reported very difficult calving had up to 2 times greater hazard compared with cows that had no problem calving. Older cows had a lower risk of culling than first-parity cows if their calving needed force or was very difficult. For first-parity cows, the total effect on survival was already evident at $150 \mathrm{~d}$ after calving. For older cows, survival in the herd after calving was less affected at $150 \mathrm{~d}$ after calving than at 365 and $730 \mathrm{~d}$ after calving. At 365 or $730 \mathrm{~d}$ after the calving of interest, cows may have calved again.

Calf Sex. Cows having single male calves had a 5 to $7 \%$ greater hazard of culling than cows having single female calves (Table 6). Cows having twins had a 23 to $46 \%$ greater hazard of culling. The increase in culling because of twinning appeared greater in first-parity cows. Twin males increased the hazard more than twin females, except in the first parity. Differences in survival were greater $365 \mathrm{~d}$ after calving than $150 \mathrm{~d}$ after calving.

Cows having male calves or twins had on average higher calving difficulty scores. Average calving difficulty scores $(1=$ no problem, $2=$ minor problem, $3=$ needed assistance, $4=$ considerable force, $5=$ very difficult) for calvings with a single female, a single male, female twins, male twins, or mixed twins were 1.33, $1.49,1.57,1.69$, and 1.65 , respectively.

Table 3. Hazard ratios (HR) of culling within the parity and percentage survival in the herd for days after conception by parity in 727 large DHI dairy herds in the eastern United States from 2001 to 2006 (pregnant cows only)

\begin{tabular}{|c|c|c|c|c|c|c|c|}
\hline Days to conception & HR & $95 \%$ CI HR ${ }^{1}$ & \multicolumn{5}{|c|}{ Survival (\%) } \\
\hline \multicolumn{8}{|l|}{ Parity 1} \\
\hline $151-270$ & 1.29 & $1.26-1.32$ & 95.6 & 91.4 & 85.9 & 80.6 & 71.8 \\
\hline $271-390$ & 1.60 & $1.56-1.65$ & 94.3 & 89.1 & 81.6 & 76.0 & 66.9 \\
\hline $391-510$ & 2.07 & $1.98-2.16$ & 92.5 & 85.9 & 76.2 & 69.4 & 60.1 \\
\hline $151-270$ & 1.21 & $1.19-1.24$ & 91.3 & 84.9 & 75.6 & 68.9 & 58.3 \\
\hline $271-390$ & 1.39 & $1.35-1.43$ & 90.0 & 82.4 & 69.8 & 62.8 & 53.0 \\
\hline $391-510$ & 1.54 & $1.47-1.62$ & 88.9 & 80.0 & 66.2 & 58.8 & 48.8 \\
\hline \multicolumn{8}{|l|}{ Parity 3} \\
\hline $30-150$ & 1 & & 90.1 & 83.1 & 75.0 & 67.9 & 55.0 \\
\hline $151-270$ & 1.14 & $1.11-1.16$ & 88.6 & 80.7 & 69.5 & 61.7 & 50.3 \\
\hline $271-390$ & 1.20 & $1.16-1.24$ & 87.7 & 78.8 & 65.1 & 57.1 & 47.2 \\
\hline
\end{tabular}

${ }^{1} 95 \%$ CI for hazard ratio. 


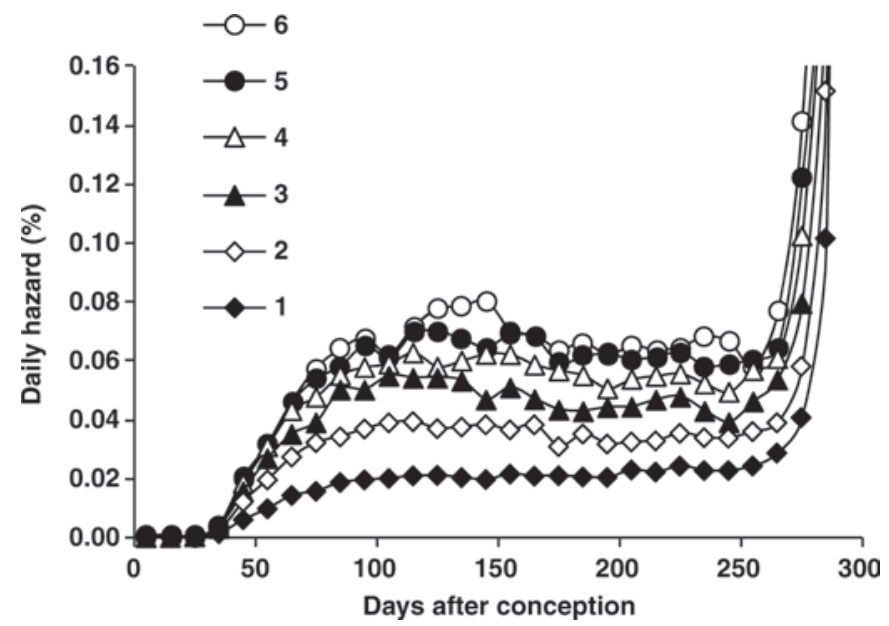

Figure 3. Daily hazard of culling in the parity for pregnant cows by parity in 727 large DHI dairy herds in the eastern United States from 2001 to 2006. Symbols denote number of parity. The sharp increase after $250 \mathrm{~d}$ after conception may indicate the risk of culling around calving while the calving event is not reported.

$\boldsymbol{S B P}$. Hazard ratios for likelihood of an SBP were not all equal $(P<0.001)$, but differences were small (Table 7). The results showed a tendency of greater hazard of culling when the likelihood of an SBP for first insemination increased. There was no clear parity effect on hazard ratios. The survival curves showed that cows in herds with no SBP had a greater probability of survival. This effect was clearer at 365 and $730 \mathrm{~d}$ after the calving of interest. This effect of SBP on survival was greater for older cows.

Herd-Days to First Insemination. Increased herd-days to first insemination decreased the hazard of culling up to $9 \%$ (Table 8 ). Parity did not have a clear effect. By $730 \mathrm{~d}$ after the calving of interest, cows in herds with on average less than $71 \mathrm{~d}$ to first insemination had a risk of being culled that was 5 percentage points greater than cows in herds with on average greater than $96 \mathrm{~d}$ to first insemination.

\section{DISCUSSION}

The objective of this observational study was to report survival curves and reproductive risk factors for culling in larger dairy herds. Risk factors were not necessarily causes for culling.

Data editing was necessarily extensive. The VWP and days to first service were calculated from only those lactations that were not completed, but Miller et al. (2007) reported results similar to those shown in Table 1. The herd-years classified as not synchronized had a fairly equal distribution of inseminations across the days of the week, which suggests an improved method to determine SBP compared with the method used by Miller et al. (2007).

Pregnancy diagnosis was primarily based on the status reported by DHI. A fraction of cows was found to be in the herd more than $50 \mathrm{~d}$ after last insemination in the parity while it was unclear whether those cows were pregnant or open. Survival analysis (not shown) revealed a much greater hazard of culling for these cows. Therefore, such cows were assumed to be open in this study.

\section{Survival and Reproductive Risk Factors}

The hazard of culling increased markedly with parity in this study in a manner similar to that reported previously (Hadley et al., 2006; Hare et al., 2006; Dechow and Goodling, 2008). The pattern of daily hazard of culling for open cows by parity was similar to that reported for all cows and all parities by Godden et al. (2003) and Dechow and Goodling (2008). Typically, an increased hazard of culling early in lactation and then again after approximately $300 \mathrm{~d}$ after calving is observed. Hazards did not peak immediately after calving as reported by Fetrow et al. (2006), but rather after a delay of 10 to 30 d. Dechow and Goodling (2008) assumed this was at least partially caused, for first-parity cows, by incomplete data recording for heifers that were culled

Table 4. Hazard ratios $(\mathrm{HR})^{1}$ and annualized risk of leaving the herd for open and pregnant cows by parity in 727 large DHI dairy herds in the eastern United States from 2001 to 2006

\begin{tabular}{lccccc}
\hline & & & & & \multicolumn{2}{c}{ Annualized risk (\%) } \\
\cline { 2 - 3 } \cline { 5 - 6 } Parity & Open & Pregnant & & Open & Pregnant \\
\hline 1 & 1 & 1 & & 36.4 & 6.9 \\
2 & $1.43(1.42-1.43)$ & $1.77(1.75-1.69)$ & & 47.9 & 11.4 \\
3 & $1.94(1.93-1.94)$ & $2.44(2.41-2.48)$ & & 63.1 & 15.2 \\
4 & $2.32(2.31-2.34)$ & $3.06(3.01-3.10)$ & & 74.2 & 18.0 \\
5 & $2.57(2.55-2.60)$ & $3.59(3.52-3.66)$ & & 80.9 & 20.0 \\
6 & $2.76(2.72-2.80)$ & $4.02(3.91-4.13)$ & & 85.5 & 21.6 \\
\hline
\end{tabular}

${ }^{1}$ Values in parentheses represent the mean and the $95 \%$ CI. 
Table 5. Hazard ratios (HR) of culling within the parity and percentage survival in the herd for days after calving by parity and calving difficulty score in 727 large DHI dairy herds in the eastern United States from 2001 to 2006

\begin{tabular}{|c|c|c|c|c|c|}
\hline \multirow[b]{2}{*}{ Calving difficulty score ${ }^{1}$} & \multirow[b]{2}{*}{$\mathrm{HR}$} & \multirow[b]{2}{*}{$95 \% \mathrm{CI} \mathrm{HR}^{2}$} & \multicolumn{3}{|c|}{ Survival (\%) } \\
\hline & & & Day 150 & Day 365 & Day 730 \\
\hline \multicolumn{6}{|l|}{ Parity 1} \\
\hline 1 & 1 & - & 91.5 & 85.0 & 64.5 \\
\hline 2 & 1.13 & $1.11-1.15$ & 90.6 & 84.3 & 63.3 \\
\hline 3 & 1.26 & $1.24-1.28$ & 89.3 & 82.9 & 61.4 \\
\hline 4 & 1.49 & $1.45-1.53$ & 86.2 & 79.4 & 57.2 \\
\hline 5 & 1.95 & $1.88-2.02$ & 82.6 & 76.0 & 54.5 \\
\hline \multicolumn{6}{|l|}{ Parity 2} \\
\hline 1 & 1 & - & 90.8 & 76.8 & 48.9 \\
\hline 2 & 1.13 & $1.11-1.16$ & 90.3 & 75.1 & 46.6 \\
\hline 3 & 1.25 & $1.22-1.28$ & 89.2 & 73.1 & 43.9 \\
\hline 4 & 1.47 & $1.41-1.53$ & 87.6 & 69.1 & 38.6 \\
\hline 5 & 1.74 & $1.66-1.82$ & 86.6 & 65.6 & 34.2 \\
\hline \multicolumn{6}{|l|}{ Parity 3} \\
\hline 1 & 1 & - & 85.8 & 67.7 & 38.5 \\
\hline 2 & 1.15 & $1.13-1.18$ & 84.7 & 65.5 & 35.4 \\
\hline 3 & 1.25 & $1.22-1.28$ & 82.9 & 63.1 & 33.0 \\
\hline 4 & 1.34 & $1.28-1.40$ & 83.2 & 61.2 & 30.1 \\
\hline 5 & 1.59 & $1.50-1.67$ & 80.5 & 56.4 & 25.7 \\
\hline
\end{tabular}

${ }^{1}$ Calving difficulty score: $1=$ no problem, $2=$ minor problem, $3=$ needed assistance, $4=$ considerable force, $5=$ very difficult.

${ }^{2} 95 \%$ CI for hazard ratio.

before their first DHI test. However, the pattern also holds for greater parity cows that have a DHI record. First-parity open cows had markedly lower hazards of culling later in lactation, an indication that they are longer eligible to get pregnant than older cows. Other studies (Rajala-Schultz and Gröhn, 1999; Schneider et al., 2007) also showed much-increased hazards for culling in open cows by days after calving.
Daily hazard of culling for pregnant cows also increased by parity, but pregnant cows were less likely to get culled than open cows. Indeed, reproduction (reproductive failure) is a major reported reason for culling (Bascom and Young, 1998; Hadley et al., 2006). Gröhn et al. (1998) and Schneider et al. (2007) reported much lower hazards for culling once a cow had conceived. Cows with longer days to conception had increased haz-

Table 6. Hazard ratios (HR) of culling within the parity and percentage survival in the herd for days after calving by parity and calf sex in 727 large DHI dairy herds in the eastern United States from 2001 to 2006

\begin{tabular}{|c|c|c|c|c|c|}
\hline \multirow[b]{2}{*}{ Calf sex } & \multirow[b]{2}{*}{$\mathrm{HR}$} & \multirow[b]{2}{*}{$95 \% \mathrm{CI} \mathrm{HR}^{1}$} & \multicolumn{3}{|c|}{ Survival (\%) } \\
\hline & & & Day 150 & Day 365 & Day 730 \\
\hline \multicolumn{6}{|l|}{ Parity 1} \\
\hline Female & 1 & - & 91.0 & 84.4 & 63.5 \\
\hline Male & 1.07 & $1.05-1.08$ & 90.2 & 83.4 & 62.4 \\
\hline Twin females & 1.46 & $1.34-1.59$ & 85.1 & 76.3 & 54.4 \\
\hline Twin males & 1.42 & $1.33-1.52$ & 85.1 & 77.3 & 55.4 \\
\hline Twin mixed & 1.36 & $1.24-1.50$ & 85.2 & 77.8 & 55.0 \\
\hline \multicolumn{6}{|l|}{ Parity 2} \\
\hline Female & 1 & - & 90.9 & 76.9 & 48.8 \\
\hline Male & 1.06 & $1.05-1.07$ & 90.0 & 75.4 & 47.4 \\
\hline Twin females & 1.28 & $1.23-1.33$ & 87.8 & 70.8 & 41.2 \\
\hline Twin males & 1.36 & $1.32-1.40$ & 87.1 & 69.3 & 40.1 \\
\hline Twin mixed & 1.29 & $1.24-1.34$ & 87.7 & 70.5 & 41.4 \\
\hline \multicolumn{6}{|l|}{ Parity 3} \\
\hline Female & 1 & - & 86.0 & 68.0 & 38.3 \\
\hline Male & 1.05 & $1.04-1.06$ & 85.1 & 66.6 & 37.4 \\
\hline Twin females & 1.23 & $1.19-1.28$ & 82.8 & 61.1 & 31.9 \\
\hline Twin males & 1.34 & $1.30-1.38$ & 80.9 & 59.2 & 30.2 \\
\hline Twin mixed & 1.28 & $1.23-1.33$ & 81.8 & 59.6 & 30.4 \\
\hline
\end{tabular}

${ }^{1} 95 \%$ CI for hazard ratio. 
Table 7. Hazard ratios (HR) of culling within the parity and percentage survival in the herd for days after calving by parity and likelihood of synchronized breeding program (SBP) in 727 large DHI dairy herds in the eastern United States from 2001 to 2006

\begin{tabular}{|c|c|c|c|c|c|}
\hline \multirow[b]{2}{*}{ SBP } & \multirow[b]{2}{*}{ HR } & \multirow[b]{2}{*}{$95 \% \mathrm{CI} \mathrm{HR}^{1}$} & \multicolumn{3}{|c|}{ Survival (\%) } \\
\hline & & & Day 150 & Day 365 & Day 730 \\
\hline \multicolumn{6}{|l|}{ Parity 1} \\
\hline Not likely & 1 & - & 91.6 & 85.1 & 66.1 \\
\hline Unlikely & 1.05 & $1.03-1.06$ & 90.5 & 83.6 & 63.3 \\
\hline Possibly & 1.01 & $0.98-1.03$ & 90.8 & 84.1 & 62.2 \\
\hline Probably & 1.05 & $1.03-1.08$ & 90.6 & 83.8 & 61.5 \\
\hline Likely & 1.01 & $0.96-1.06$ & 90.7 & 84.1 & 61.1 \\
\hline \multicolumn{6}{|l|}{ Parity 2} \\
\hline Not likely & 1 & - & 91.0 & 77.9 & 52.0 \\
\hline Unlikely & 1.02 & $1.01-1.04$ & 90.6 & 76.6 & 49.3 \\
\hline Possibly & 1.00 & $0.98-1.03$ & 90.2 & 75.0 & 46.9 \\
\hline Probably & 1.02 & $0.99-1.04$ & 90.0 & 75.0 & 45.8 \\
\hline Likely & 1.05 & $1.00-1.10$ & 89.8 & 74.1 & 44.4 \\
\hline \multicolumn{6}{|l|}{ Parity 3} \\
\hline Not likely & 1 & - & 86.8 & 70.1 & 41.8 \\
\hline Unlikely & 1.00 & $0.99-1.02$ & 86.1 & 68.0 & 39.2 \\
\hline Possibly & 1.00 & $0.98-1.03$ & 84.9 & 65.7 & 36.2 \\
\hline Probably & 1.02 & $1.00-1.05$ & 84.2 & 64.9 & 34.8 \\
\hline Likely & 1.08 & $1.03-1.14$ & 83.3 & 63.6 & 33.7 \\
\hline
\end{tabular}

${ }^{1} 95 \%$ CI for hazard ratio.

ards of culling during pregnancy, a finding also reported by Rajala-Schultz and Gröhn (1999) and Sewalem et al. (2008). Cows that conceive late in lactation may be more at risk for overconditioning and, consequently, for health problems that lead to forced removal from the herd.

Cows that were culled before pregnancy diagnoses were considered open. Therefore, the hazard of culling of pregnant cows was close to 0 for approximately 1 mo after conception. The hazard of culling increased greatly at the end of the gestation period. Cows that were culled around calving may not have been reported as having calved. Schneider et al. (2007) also reported a much-increased hazard for culling after $240 \mathrm{~d}$ of gestation.

The hazard ratios shown in Tables 5 to 8 generally agreed with the differences in survival estimates within the same parity. Hazard ratios were not proportional, as

Table 8. Hazard ratios (HR) of culling within the parity and percentage survival in the herd for days after calving by parity and herd-days to first insemination in 727 large DHI dairy herds in the eastern United States from 2001 to 2006

\begin{tabular}{llcccc}
\hline & & & \multicolumn{3}{c}{ Survival (\%) } \\
\cline { 4 - 6 } Herd-days to first insemination & $\mathrm{HR}$ & $95 \% \mathrm{CI} \mathrm{HR}^{1}$ & Day 150 & Day 365 & Day 730 \\
\hline Parity 1 & & & & & \\
$<71$ & 1 & - & 89.8 & 82.8 & 60.6 \\
$71-79$ & 1.00 & $0.98-1.02$ & 90.8 & 84.1 & 62.4 \\
$79-86$ & 0.98 & $0.96-1.00$ & 91.0 & 84.2 & 63.4 \\
$86-96$ & 0.98 & $0.96-1.00$ & 91.0 & 84.1 & 64.3 \\
$>96$ & 0.93 & $0.91-0.96$ & 91.4 & 84.7 & 65.5 \\
Parity 2 & & & & & \\
$<71$ & 1 & - & 89.9 & 74.6 & 45.6 \\
$71-79$ & 0.98 & $0.97-1.00$ & 90.3 & 75.4 & 46.8 \\
$79-86$ & 0.98 & $0.96-0.99$ & 90.5 & 76.3 & 48.5 \\
$86-96$ & 0.97 & $0.95-0.99$ & 90.5 & 76.6 & 49.7 \\
$>96$ & 0.93 & $0.90-0.95$ & 90.9 & 77.8 & 51.5 \\
Parity 3 & & & & & \\
$<71$ & 1 & -1 & 84.5 & 64.9 & 35.3 \\
$71-79$ & 0.98 & $0.96-0.99$ & 85.1 & 66.1 & 36.3 \\
$79-86$ & 0.97 & $0.95-0.99$ & 85.4 & 66.8 & 37.5 \\
$86-96$ & 0.97 & $0.95-0.99$ & 85.9 & 68.0 & 39.4 \\
$>96$ & 0.91 & $0.89-0.94$ & 86.9 & 70.4 & 41.9 \\
\hline
\end{tabular}

${ }^{1} 95 \%$ CI for hazard ratio. 
shown by the LIFETEST procedure. In general, the risk factor of interest had a greater effect early in lactation than later in lactation. All risk factors of interest had significant effects on the hazard of culling. Differences in hazards and survival curves cannot be attributed only to the risk factor of interest because other factors, such as cow comfort, may explain differences.

Greater calving difficulty resulted in an increased hazard of culling. Sewalem et al. (2008) reported very similar results for Canadian Holsteins. In their study, hazard ratios for functional survival were 1.92 for calvings that needed surgery versus calving that occurred unassisted. López de Maturana et al. (2007) reported hazard ratios of up to 2.5 for first-parity calvings that needed assistance compared with unassisted calvings in Spanish Holsteins. Calving difficulty score was less important in older cows. A similar trend was found in the current study. Results of other studies with similar findings were summarized by Beaudeau et al. (2000). Cows calving with greater difficulty typically had larger calves (Sewalem et al., 2008).

Cows having single male calves or twins were more likely to get culled than cows having female calves. Of the $1,728,979$ calvings in the first 3 parities with reported calf sex, $3.1 \%$ ended in twin births. Twinning increased by parity number, with $0.8,4.2$, and $5.8 \%$ of calvings for parities 1,2 , and 3 , respectively. These percentages are probably underestimated because coding for calf sex was not completely clear. In a review of the literature, Fricke (2001) also reported that older cows had an increased risk of twinning, similar to the data in this study. Further, cows that had twins were more likely to be culled than cows that had single calves. Cow milk production and fertility was reduced as well (Fricke, 2001).

The distribution of SBP showed a greater fraction of herds at least possibly using estrus synchronization than in the study by Miller et al. (2007). The USDA (2009) reported that more than one-half of operations $(57.6 \%)$ used an SBP for at least some cows during 2007. Thursday and Friday were the preferred days of the week to inseminate cows in herds using an SBP, which supports the use of protocols that avoid administration of drugs or inseminations during weekends. The use of SBP increased over time. Miller et al. (2007) also reported an increase in the use of SBP from 1996 to 2005 , with $27.5 \%$ of herds at least possibly using an SBP in 2005. That study included herds with fewer than 200 cows. Therefore, the use of SBP appears to be greater in larger herds.

The hazard of culling was slightly greater in herds that at least possibly used an SBP. The effect of likelihood of the use of an SBP on reproductive performance was not evaluated in this study. Miller et al. (2007) re- ported a decrease in the days to first insemination and days to conception when an SBP was used. Meadows et al. (2007) reported an increased pregnancy rate in Ohio herds that used an SBP.

Herds with shorter herd-average days to first insemination had slightly increased hazards of culling. In Holstein herds in Canada, cows with greater than 120 $\mathrm{d}$ to first insemination had a slightly increased risk of culling (Sewalem et al., 2008). This effect could not be evaluated in this study because of uncertainty about first insemination dates in completed lactations.

\section{Statistical Analysis}

The use of the GLIMMIX procedure for survival analysis allows for inclusion of random and herd-level effects in a Cox regression model that was otherwise not available with SAS. Advantages of using GLIMMIX for survival analysis are that 1) it has an exact method for handling tied data, 2) incorporating timedependent covariates is easy and intuitive, 3) it allows for inclusion of random and herd-level effects, and 4) computations are quite manageable with large data sets such as the one used in this study. The inclusion of a random herd effect creates a shared frailty model (Dohoo et al., 2003).

Parametric survival models can be fit with the GLIMMIX procedure as well. For example, a Weibull model is specified by including the log of survival time as a covariate (Allison, 1995). In this study, a Cox regression model was preferred over a parametric model because the baseline hazard function would not have to be specified and, therefore, results were more robust (Allison, 1995).

When a time-dependent effect (year) is used in a GLIMMIX Cox regression model, it is a nonproportional hazards model (Allison, 1995). Because time is treated like any other effect in the model, the approach remains an ordinary logit regression analysis. The risk factor of interest was stratified in the PHREG procedure for estimating the survival curves. Therefore, nonproportionality of hazards was not an issue (Allison, 1995).

\section{CONCLUSIONS}

Survival and reproductive risk factors for culling in Holstein dairy herds with at least 200 cows were described. The hazard of culling increased with parity number. Cows in their sixth parity had 3 times greater hazards than cows in their first parity. Medium remaining productive life for cows calving in parity 1 to 6 were 907, 697, 553, 469, 423, and 399 d, respectively. Daily hazards of culling first peaked approximately $30 \mathrm{~d}$ after calving and then again later in lactation, after $280 \mathrm{~d}$, for 
older cows. Hazards for first-parity cows peaked earlier, around d 10 after calving, and first-parity cows had lower risks of culling later in lactation than older cows. Pregnant cows had 3 to 7 times lower hazards of culling than open cows. Hazards of culling were increased for cows that had greater calving difficulty, gave birth to males or twins, were in herds with shorter days to first insemination, or had longer days to conception. The possible to likely use of an SBP increased from $21.9 \%$ in 2001 to $41.4 \%$ in 2006 . Cows in herds that did not use an SBP had slightly lower risks of culling than those in herds that at least possibly used an SBP.

\section{ACKNOWLEDGMENTS}

We thank Dairy Records Management Systems in Raleigh, North Carolina, for kindly providing updated lactation records. Pfizer Animal Health (New York, $\mathrm{NY}$ ) is acknowledged for funding the study.

\section{REFERENCES}

Allison, P. D. 1995. Survival Analysis Using the SAS System: A Practical Guide. SAS Institute Inc., Cary, NC.

Bascom, S. S., and A. J. Young. 1998. A summary of the reasons why farmers cull cows. J. Dairy Sci. 81:2299-2305.

Beaudeau, F., H. Seegers, V. Ducrocq, C. Fourichon, and N. Bareille. 2000. Effects of health disorders on culling in dairy cows: A review and critical discussion. Ann. Zootech. 49:293-311.

Collett, D. 2003. Modelling Survival Data in Medical Research. 2nd ed. Chapman and Hall/CRC, Boca Raton, FL.

De Vries, A. 2006. Economic value of pregnancy in dairy cattle. J. Dairy Sci. 89:3876-3885.

Dechow, C. D., and R. C. Goodling. 2008. Mortality, culling by sixty days in milk, and production profiles in high- and low-survival Pennsylvania herds. J. Dairy Sci. 91:4630-4639.

Dohoo, I., W. Martin, and H. Stryhn. 2003. Veterinary Epidemiologic Research. Atlantic Veterinary College, Charlottetown, Prince Edward Island, Canada.

Ducrocq, V., and J. Sölkner. 1994. The survival kit-A Fortran package for the analysis of survival data. Pages 51-52 in Proc. 5th World Congr. Genet. Appl. Livest. Prod. Vol. 22. Dept. Anim. Poultry Sci., University of Guelph, Guelph, Ontario, Canada.

Fetrow, J., K. V. Nordlund, and H. D. Norman. 2006. Invited review: Culling: Nomenclature, definitions, and recommendations. J. Dairy Sci. 89:1896-1905.
Fricke, P. M. 2001. Review: Twinning in dairy cattle. Prof. Anim. Sci. 7:61-67.

Godden, S. M., S. C. Stewart, J. F. Fetrow, P. Rapnicki, R. Cady, W. Weiland, H. Spencer, and S. W. Eicker. 2003. The relationship between herd rbST supplementation and other factors and risk for removal for cows in Minnesota Holstein dairy herds. Pages 55-64 in Proc. Four-State Nutr. Conf., LaCrosse, WI. MidWest Plan Service Publ. MWPS-4SD16. Midwest Plan Service, Ames, IA

Gröhn, Y. T., S. W. Eicker, V. Ducrocq, and J. A. Hertl. 1998. Effect of diseases on the culling of Holstein dairy cows in New York state. J. Dairy Sci. 81:966-978.

Hadley, G. L., C. A. Wolf, and S. B. Harsh. 2006. Dairy cattle culling patterns, explanations, and implications. J. Dairy Sci. 89:22862296.

Hare, E., H. D. Norman, and J. R. Wright. 2006. Survival rates and productive herd life of dairy cattle in the United States. J. Dairy Sci. 89:3713-3720.

López de Maturana, E., E. Ugarte, and O. González-Recio. 2007. Impact of calving ease on functional longevity and herd amortization costs in Basque Holsteins using survival analysis. J. Dairy Sci. 90:4451-4457.

Meadows, C., P. Rajala-Schultz, G. S. Frazer, R. W. Meiring, and K. H. Hoblet. 2007. Evaluation of a contract breeding management program in selected Ohio dairy herds with event-time analysis. I. Cox proportional hazards models. Prev. Vet. Med. 77:145-160.

Miller, R. H., H. D. Norman, M. T. Kuhn, J. S. Clay, and J. L. Hutchinson. 2007. Voluntary waiting period and adoption of synchronized breeding in dairy herd improvement herds. J. Dairy Sci. 90:1594-1606.

MSWFT. 2009. Dairy Farm Operating Trends for the Year ended December 31, 2008. Moore Stephens Wurth Frazer and Torbet LLP, Visalia, CA.

Rajala-Schultz, P. J., and Y. T. Gröhn. 1999. Culling of dairy cows. Part III. Effect of diseases, pregnancy status and milk yield culling in Finnish Ayrshire cows. Prev. Vet. Med. 41:295-309.

SAS Institute Inc. 2008. SAS/STAT 9.2. User's Guide. SAS Institute Inc., Cary, NC.

Schneider, M. del P., E. Strandberg, U. Emanuelson, K. Grandinson, and K. Roth. 2007. The effect of veterinary-treated clinical mastitis and pregnancy status on culling in Swedish dairy cows. Prev. Vet. Med. 80:179-192.

Sewalem, A., F. Miglior, G. J. Kistemaker, P. Sullivan, and B. J. Van Doormaal. 2008. Relationship between reproduction traits and functional longevity in Canadian dairy cattle. J. Dairy Sci. 91:1660-1668.

USDA. 2009. Dairy 2007, Part IV: Reference of Dairy Cattle Health and Management Practices in the United States, 2007. Animal and Plant Health Inspection Service, Centers for Epidemiology and Animal Health, Fort Collins, CO.

Weigel, K. A., R. W. Palmer, and D. Z. Caraviello. 2003. Investigation of factors affecting voluntary and involuntary culling in expanding dairy herds in Wisconsin using survival analysis. J. Dairy Sci. $86: 1482-1486$. 